\title{
Effect of Captopril on Serum Lipid Levels and Cardiac Mitochondrial Oxygen Consumption in Experimentally-Induced Hypercholesterolemia in Rabbits
}

\author{
Z. KOJIC ${ }^{1}$, K. GOPCEVIC ${ }^{2}$, D. MARINKOVIC ${ }^{3}$, G. TASIC ${ }^{1}$ \\ ${ }^{1}$ Institute of Physiology, School of Medicine, University of Belgrade, ${ }^{2}$ Institute of Biochemistry, \\ School of Medicine, University of Belgrade, ${ }^{3}$ Institute of Pathology, Faculty of Veterinary \\ Medicine, University of Belgrade, Belgrade, Serbia
}

Received January 18, 2011

Accepted March 30, 2011

On-line July 19, 2011

\begin{abstract}
Summary
Angiotensin converting enzyme inhibitors are widely used in therapy of cardiovascular diseases. However, the consensus on effects of these inhibitors in control of myocardial oxygen consumption during the process of experimental hypercholesterolemia and under the condition of endothelial dysfunction has not been reached. Here we examined effects of captopril, an angiotensin converting enzyme inhibitor, on serum lipid levels and oxygen consumption rate in mitochondria isolated from heart of rabbits treated by hypercholesterolemic diet. During the twelve-week period, the Chinchilla male rabbits were daily treated by saline (controls); $1 \%$ cholesterol diet; $5 \mathrm{mg} / \mathrm{kg} /$ day captopril or $1 \%$ cholesterol $+5 \mathrm{mg} / \mathrm{kg} / \mathrm{day}$ captopril. Total- and high-density lipoprotein cholesterol and triglyceride in serum were measured spectrophotometricly. The left ventricle mitochondrial fraction was isolated and myocardial oxygen consumption was measured by Biological Oxygen Monitor. Mitochondria isolated from hearts of rabbits exposed to hypercholesterolemic diet showed significantly reduced respiration rates (state 3 and state 4 ) with altering adenosine diphosphate/oxygen ratio, whereas the respiratory control ratio was not affected when compared to controls. Mitochondria from cholesterol/captopril-treated animals showed significantly reduced respiration rates without altering adenosine diphosphate/oxygen ratio index or respiratory control ratio. Although captopril did not exert the favorable effect on serum lipid levels in cholesterol-treated animals, it restored the mitochondrial oxygen consumption. Further studies should be performed to define the underlying physiological and/or pathophysiological mechanisms and clinical implications.
\end{abstract}

\section{Key words}

ACE inhibitors - Mitochondria, Heart • Oxygen consumption • Hypercholesterolemia • Rabbits

\section{Corresponding author}

Z. Kojic, Institute of Physiology, School of Medicine, University of Belgrade, Visegradska 26, 11000 Belgrade, Serbia. Fax: +381 11 3611 262. E-mail: zvezdanak@med.bg.ac.rs

\section{Introduction}

The importance of plasma lipoprotein and lipid metabolism abnormalities characterized by hyperlipidemia and/or hypercholesterolemia as the cause of coronary heart diseases and potential atherosclerosis is supported by a number of epidemiological and population-based studies (Alves et al. 2010, Zeng et al. 2010). Rabbits under hypercholesterolemia-inducing diets have been largely used as an experimental model to study the development of human atherosclerosis (Dornas et al. 2010). In general, development of atherosclerosis is regulated by multiple complex mechanisms, including endothelial dysfunction with impaired nitric oxide (NO) bioavailability, oxidative stress, inflammation, hemostasis, and insulin resistance (Montecucco et al. 2009). Reciprocal relationships between endothelial dysfunction and insulin resistance as well as cross-talk between hyperlipidemia and the rennin-angiotensinaldosterone system may contribute to development of atherosclerosis (Koh et al. 2010). 
The renin-angiotensin-aldosterone system is a major endocrine/paracrine system involved in the regulation of a myriad of cardiovascular processes (Schmieder et al. 2007). Its role in the pathogenesis of hypertension, cardiac hypertrophy, and atherosclerosis is well established. Because angiotensin converting enzyme inhibitors (ACE-I) exhibit cardioprotective, vasculoprotective, antiatherogenic effects and contribute to tissue protection, they are widely used in therapy of cardiovascular disease (Shi et al. 2010, Sharpe 1993). Antihypertensive and cardioprotective effects of ACE-I have usually been attributed to the inhibition of angiotensin II (Ang II)-mediated effects at vascular or ventricular angiotensin type $1\left(\mathrm{AT}_{1}\right)$ receptors. Another important mechanism involves Ang II-induced interactions with the bradykinin - kallikrein system, which might include alterations of cardiac oxygen consumption during ACE inhibition due to a modulation of NO synthase activity (Morais et al. 2010, Manolis et al. 2010).

In addition to inhibiting Ang II production (Shi et al. 2010), ACE-I also reduce kinins breakdown, resulting in local accumulation of kinins on the endothelial cell surface (Manolis et al. 2010). Response of endothelial cells to kinins stimulation is complex and one of the responses is kinins-induced NO synthesis (Vanhoutte 2010). The importance of endothelial NO in control of oxygen consumption $\left(\mathrm{QO}_{2}\right)$ was suggested in 1994, when it was shown that inhibition of NO synthesis resulted in $40 \% \mathrm{QO}_{2}$ increase in the posterior dog legs (King et al. 1994) and $25 \%$ increase in the whole body, accompanied with $1.1^{\circ} \mathrm{C}$ increase in body temperature (Shen et al. 1994, 1995). Therefore, it has been postulated that endothelial NO permanently inhibits tissue respiration in a tonic manner, and that constitutive NO endothelial production regulates the mitochondrial function in parenchimal cells of the peripheral tissues.

However, the consensus on the effect of ACE inhibitors in control of tissue cellular respiration under the condition of endothelial dysfunction during the process of atherosclerosis and hypercholesterolemia has not been reached. Mitochondria play a central role in the energy metabolism of all tissues by controlling the production of ATP, and experimentally isolated mitochondria are commonly used to evaluate the metabolic activities of brain, heart, and muscle tissues in both normal and diseased states (Johannsen and Ravussin 2009). The aim of this study was to determine the influence of captopril, an ACE inhibitor, in the animals treated by hypercholesterolemic diet on serum lipid levels and oxygen consumption rate in isolated mitochondria from heart cells.

\section{Material and Methods}

\section{Chemicals}

All chemicals were obtained from Sigma (St. Louis, MO).

\section{Animal and diets}

Male Chinchilla rabbits $(n=40) 9$ week old and weighing $2.0 \pm 0.27 \mathrm{~kg}$ (mean $\pm \mathrm{SD}$ ) were bred in the Animal Center of the Institute of Physiology, School of Medicine, Belgrade. Rabbits were housed individually in standard stainless steel cages at $24^{\circ} \mathrm{C}$ with a $12-\mathrm{h}$ light:dark cycle (lights on, 06.30-18.30 h). All experiments were performed in accordance with a protocol approved by the local Ethics Committee and in accordance with the European Guidelines on Laboratory Animal Care. During 12 weeks of treatment, rabbits were fed the commercial rabbit chow diet (Zemun, Serbia) and orally received once a day a single dose of the following supplementation: physiologic saline (control, group A, $\mathrm{n}=10$ ); high cholesterol diet (1\%), (group $\mathrm{B}, \mathrm{n}=10)$ ), high cholesterol $\operatorname{diet}(1 \%)$ plus captopril 2 hours later (group $\mathrm{C}, \mathrm{n}=10$ ) or captopril only (group $\mathrm{D}, \mathrm{n}=10$ ). Captopril was given in a dose $5 \mathrm{mg} / \mathrm{kg}$ body weight in $0.5 \mathrm{ml}$ saline per day.

\section{Blood samples}

At the end of the 12 week treatment protocol, the rabbits were anesthetized with katamine-HCl. Blood samples were drawn and serum was obtained by centrifuging the blood at $3,000 \mathrm{rpm}$ for $20 \mathrm{~min}$ at $4{ }^{\circ} \mathrm{C}$. The serum samples were stored at $-70^{\circ} \mathrm{C}$ until analyzed.

\section{Serum lipid profile}

Serum total cholesterol (TC), triglyceride (TG) and high-density lipoprotein cholesterol (HDL-C) were measured by an enzymatic "end point" kinetic spectrophotometric method using Rx Monza Clinical Chemistry Analyser (Randox Laboratories Ltd, UK) and the commercial kit provided by the Randox, UK. Serum LDL concentrations were calculated according to Friedewald et al. (1972). Results are reported as means of duplicate samples for each animal.

\section{Tissue samples and mitochondrial isolation}

At the conclusion of the 12 week treatment protocol, the heart was rapidly removed. The left ventricle 
Table 1. Serum lipid concentrations in rabbits fed a normal diet (group A), high cholesterol diet (group B), the high cholesterol diet plus captopril (group C) or captopril only (group D) for $12 \mathrm{wk}$ : at the end of treatment ${ }^{1}$.

\begin{tabular}{lcccc}
\hline Variable & Group A & Group B & Group C & Group D \\
\hline$n$ & 10 & 10 & 10 & 10 \\
$T C, \mathrm{mmol} / \mathrm{l}$ & $2.09 \pm 0.07^{\mathrm{b}}$ & $20.67 \pm 1.04^{\mathrm{a}}$ & $15.72 \pm 1.35^{\mathrm{a}}$ & $1.98 \pm 0.07^{\mathrm{b}}$ \\
$L D L-C, \mathrm{mmol} / \mathrm{l}$ & $2.34 \pm 0.03^{\mathrm{b}}$ & $15.34 \pm 1.36^{\mathrm{a}}$ & $13.19 \pm 1.20^{\mathrm{a}}$ & $2.24 \pm 0.06^{\mathrm{b}}$ \\
$H D L-C, \mathrm{mmol} / \mathrm{l}$ & $0.92 \pm 0.02^{\mathrm{a}}$ & $1.96 \pm 0.24^{\mathrm{b}}$ & $1.87 \pm 0.23^{\mathrm{b}}$ & $0.88 \pm 0.03^{\mathrm{a}}$ \\
$L D L / \mathrm{HDL}$ & $2.54 \pm 0.73^{\mathrm{c}}$ & $8.03 \pm 0.74^{\mathrm{a}}$ & $7.99 \pm 0.83^{\mathrm{a}}$ & $2.55 \pm 0.67^{\mathrm{b}}$ \\
$T G, \mathrm{mmol} / \mathrm{l}$ & $0.86 \pm 0.17^{\mathrm{b}}$ & $1.86 \pm 0.17^{\mathrm{a}}$ & $1.48 \pm 0.16^{\mathrm{a}}$ & $0.91 \pm 0.15^{\mathrm{a}}$ \\
\hline
\end{tabular}

${ }^{1}$ Values are means \pm S.E.M. Values in a row with unlike superscripts $(a, b, c)$ differ, $P<0.05$. Abbreviations used: TG, triglyceride; TC, total cholesterol; C, cholesterol

was dissected from the rest of the heart and used for the mitochondrial isolation by differential centrifugation as described by Kowaltowski et al. (2001). Briefly, the tissue was minced with scissors and washed twice with ice-cold Krebs-Ringer solution, then placed in ice-cold buffer containing $300 \mathrm{mM}$ sucrose, $10 \mathrm{mM} \mathrm{K} \mathrm{K}^{+}$-HEPES buffer, $\mathrm{pH}$ 7.2, and $1 \mathrm{mM} \mathrm{K}^{+}$-EGTA, $\mathrm{pH}$ 8.0. The minced tissue was homogenized by using a blender-type homogenizer (QUIAGEN $\mathrm{GmbH}$ ) for 10-15 $\mathrm{s}$ and in a glass-grinding vessel with a motor-driven pestle for $5-10 \mathrm{~s}$ at $4{ }^{\circ} \mathrm{C}$. Nagarse ( $4 \mathrm{mg} / 20 \mathrm{ml}$ homogenate) was added to the homogenate, which was then incubated on ice for $10 \mathrm{~min}$. The homogenate was then centrifuged (Heraeus Laboratory Centrifuge, UK) for $4 \mathrm{~min}$ at $750 \mathrm{~g}(1,500$ $\mathrm{rpm})$. The supernatant was saved, and $1 \mathrm{mg} / \mathrm{ml}$ BSA was added. The supernatant was then recentrifuged for $4 \mathrm{~min}$ at $750 \mathrm{~g}$, and the pellet was discarded. The resulting supernatant was then centrifuged at 9,000 $g(9,500 \mathrm{rpm})$ for $10 \mathrm{~min}$ at $4{ }^{\circ} \mathrm{C}$. The mitochondrial pellet was then resuspended in ice-cold buffer $A$ containing $1 \mathrm{mg} / \mathrm{ml} \mathrm{BSA}$ and recentrifuged at $9,000 \mathrm{~g}$ at $4{ }^{\circ} \mathrm{C}$ two times. The final pellet was suspended in $3 \mathrm{ml}$ of respiration medium containing (in mM) 250 sucrose, $2 \mathrm{KH}_{2} \mathrm{PO}_{4}, 10 \mathrm{MgCl}_{2}, 20$ $\mathrm{K}^{+}$-HEPES buffer, $\mathrm{pH} 7.2,0.5 \mathrm{~K}^{+}$-EGTA, pH 8.0, at $4{ }^{\circ} \mathrm{C}$. Protein was determined by the Lowry Folin phenol reagent method using BSA as a standard (Lowry et al. 1951).

\section{Measurement of mitochondrial respiration}

Mitochondrial oxygen consumption was measured using Biological Oxygen Monitor System (Model 5300: YSI Inc, Ohio, USA). In order to measure oxygen consumption mediated by complex I of the mitochondrial electron transport chain, glutamate and malate $(5 \mathrm{mM})$ were added to the respiration media before the mitochondria. Isolated rabbit heart mitochondria were suspended at $1 \mathrm{mg} / \mathrm{ml}$ in a in potassium chloride buffer $\left(30^{\circ} \mathrm{C}\right.$ ) containing (in $\left.\mathrm{mM}\right) 125 \mathrm{KCl}, 20$ Hepes, $2 \mathrm{~K}_{2} \mathrm{HPO}_{4}, 0.01$ EGTA, and $1 \mathrm{MgCl}_{2}(\mathrm{pH}$ 7.2) and mitochondrial state 4 rates of $\mathrm{O}_{2}$ uptake (resting or controlled respiration) were determined. Subsequently, $1 \mathrm{mM}$ ADP was added for the determination of state 3 rates of $\mathrm{O}_{2}$ uptake (active respiration). After measuring states 3 and state 4 , the respiration activity of heart mitochondria was assessed by measuring respiratory control ratio (RCR): the respiratory rate (State 3) in the presence of ADP compared to the rate (State 4) following the expenditure of ADP and the adenosine diphosphate/ oxygen (ADP/O) ratio: the ratio of ADP removed from the media to the amount of oxygen consumed, according to the Estabrook method. Software Digiscope for Windows (version 2.0.6) was used for dynamic measurement (realtime measurement), for calculation of oxygen uptake and for presentation of oxygraphic curves. The results of oxygen consumption were expressed in ng atoms of consumed oxygen per minute per milligram of protein of thick mitochondrial suspension.

\section{Statistical analysis}

Statistical analysis was performed by using the SPSS (version 17.0.1) software package (IBM, NY). The means \pm SEM for all data were calculated for all variables. Statistical significance was assessed by using repeated-measures ANOVA with $P<0.05$.

\section{Results}

\section{Serum lipids}

Table 1 shows lipid levels in the four study groups. The cholesterol feeding (group B) increased the values of TC and LDL-C by roughly 10- and 7-fold, 

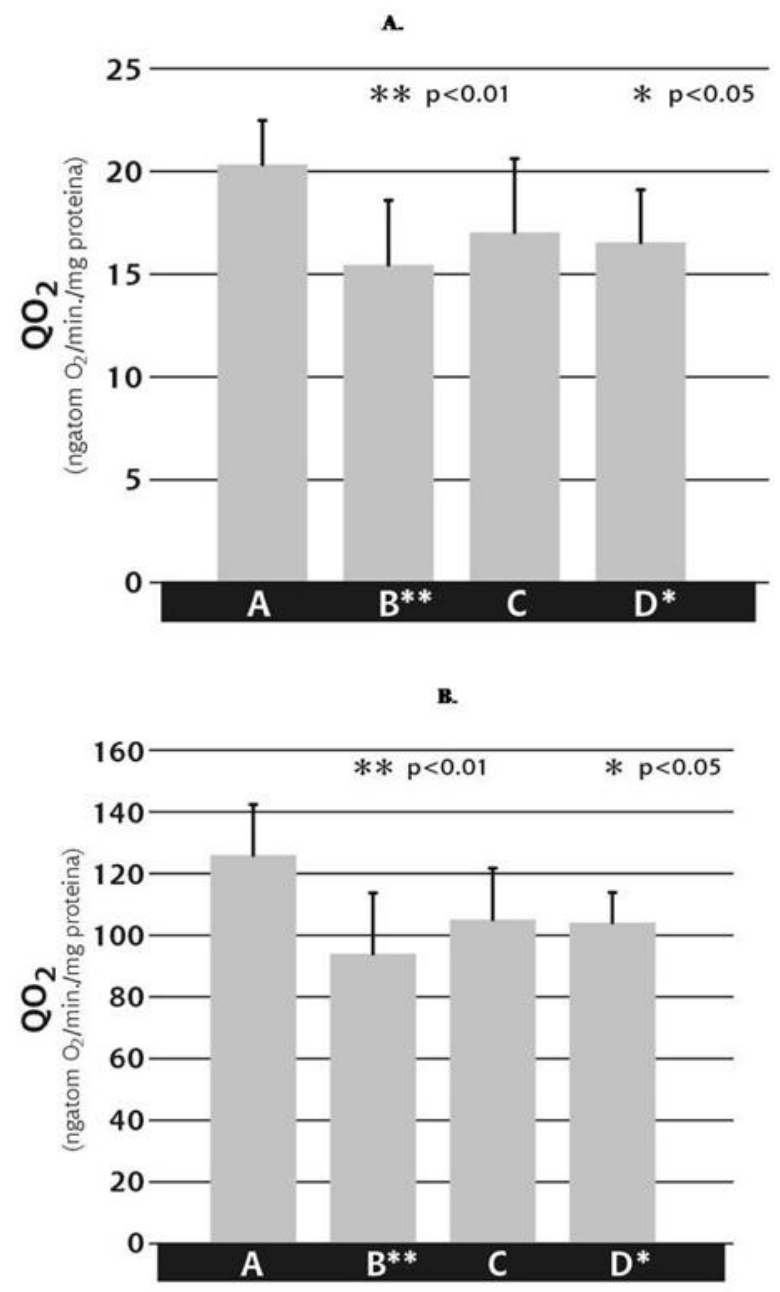

Fig 1. Mitochondrial State 4 (Panel A) and State 3 (Panel B) oxygen consumption in malate (complex I substrate)-energized mitochondria. Values are means $\pm \mathrm{SEM}$ (in ngatom $\mathrm{O}_{2}{ }^{*} \mathrm{~min}^{-1} * \mathrm{mg}$ mitochondrial protein ${ }^{-1}$ ); $n=10$ animals/group; $* * P<0.01$ vs. control. Isolated mitochondrial oxygen consumption was measured in control hearts (group A), cholesterol-supplemented (B), cholesterol + captopril supplemented (C) and captoprilsupplemented (D) hearts.

respectively. It also altered the HDL-C and LDL/HDL index by $2.2-$ and 3.2-fold, respectively. The serum triglyceride values increased 2 -fold. The circulating TC, LDL, HDL-C and triglyceride concentrations in rabbits fed hypercholesterolemic diet were significantly higher than those in control rabbits (group A) $(P<0.05)$. There were no significant differences in serum TC, LDL-C, HDL-C and TG concentrations or LDL/HDL ratio among the groups $\mathrm{B}$ and $\mathrm{C}(\mathrm{P}>0.05)$. Treatment with captopril only did not significantly affect the lipid profile compared with control rabbits $(\mathrm{P}>0.05)$.

\section{Mitochondrial oxygen consumption}

State 4 (basal) mitochondrial oxygen consumption significantly decreased in group $\mathrm{B}(P<0.01)$ when compared with group A $(15.45 \pm 2.03$ vs. $20.33 \pm 2.15$ ). The captopril treatment protocol (group D) decreased state 4 mitochondrial oxygen consumption to less extent compared with controls $(P<0.05)$. However, no significant difference in the state 4 mitochondrial oxygen consumption was observed between group $\mathrm{C}$ and A (p>0.05) (Fig. 1A). State 3 (ADP stimulated) mitochondrial oxygen consumption significantly decreased in group B ( $P<0.01$ vs. control) (Fig. 1B). Captopril treatment protocol to the less extend decreased the state 3 (ADP stimulated) mitochondrial oxygen consumption $(P<0.05$ vs. control). However, no significant difference in mitochondrial oxygen consumption between groups $\mathrm{C}$ and $\mathrm{A}$ was observed ( $>>0.05$ ) (Fig. 1B). No significant difference in RCR was found within or among four groups after 12 week treatment (Fig. 2A). ADP/O ratio in group B significantly decreased $(P<0.01$ vs. group A) to $2.07 \pm 0.40$. No significant difference in $\mathrm{ADP} / \mathrm{O}$ ratios was found within or among control (3.24 \pm 0.24$)$, high cholesterol diet + captopril (2.78 \pm 0.33$)$ and captopril (3.20 \pm 0.44$)$ groups after 12-week treatment (Fig. 2B).

\section{Discussion}

In the present study, we evaluated the effects of ACE inhibition by captopril in rabbits fed a highcholesterol diet on serum lipid profile and myocardial oxygen consumption. Rabbits are an animal species that have several aspects similar to those of humans in regard to lipoprotein metabolism (Moghadasian et al. 2001). During a typical atherogenic diet (supplementation of $0.5 \%$ to $4 \%$ cholesterol per weight for approximately 8 to 16 weeks), rabbits rapidly become hypercholesterolemic (plasma cholesterol $>1,000 \mathrm{mg} / \mathrm{dl}$ ) (Chapman et al. 1980). However, careful extrapolations should be made in relation to the degree of hypercholesterolemia produced in laboratory animals, because they exceed the levels usually found in humans.

Our results are in general agreement with suggestions concerning the rabbit serum lipid profile. The hypercholesterolemic rabbits had significantly higher levels of TC, LDL-C, HDL-C, and triglycerides than the control group. In contrast, there were no significant differences in serum lipids among the groups fed the high cholesterol - and high cholesterol + captopril diets, respectively. At the end of treatment, the LDL/HDL-ratio was significantly higher in groups $\mathrm{B}$ and $\mathrm{C}$ than in groups 

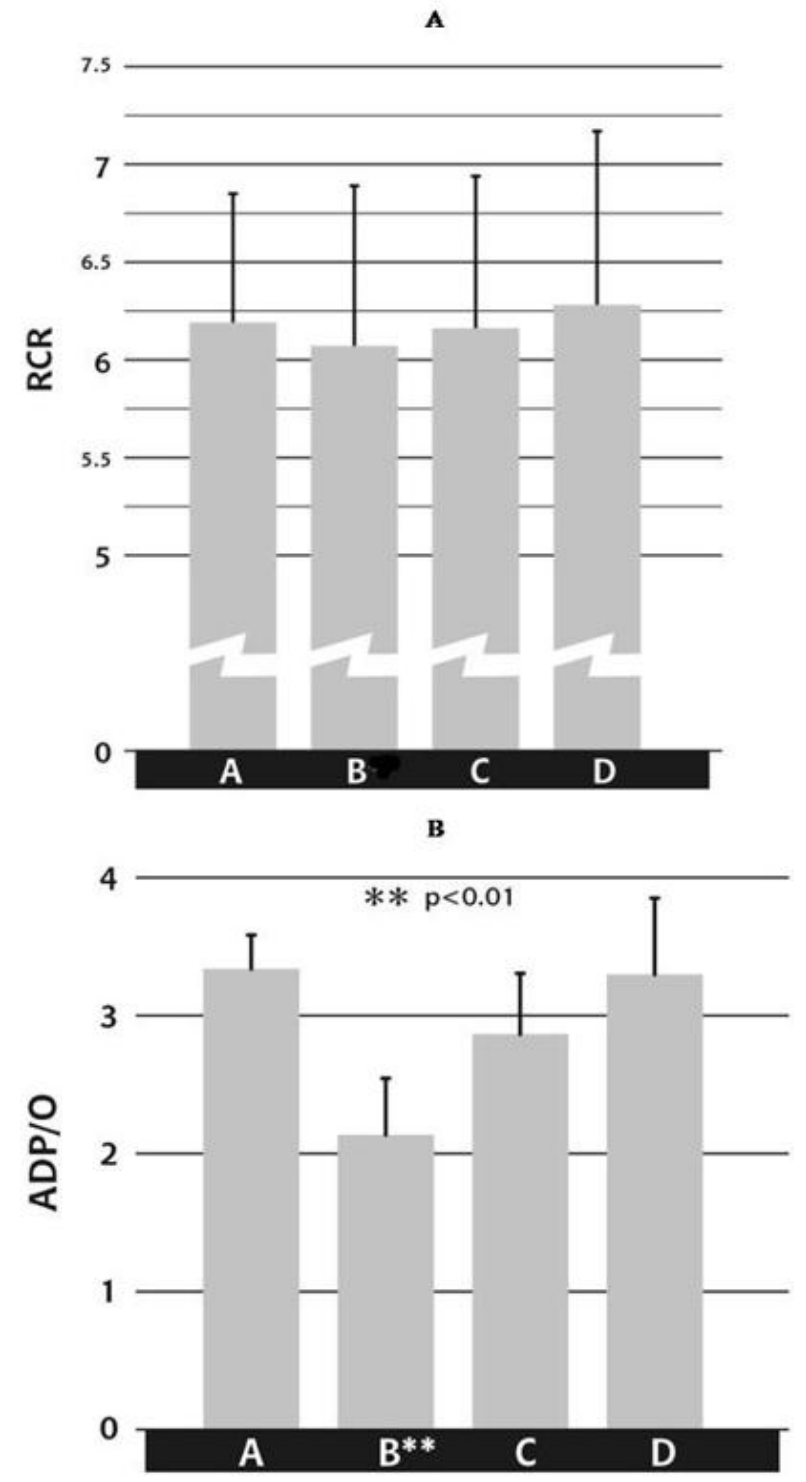

Fig. 2. Respiratory control ratio (A) and $A D P / O$ ratio (B) in malate (complex I substrate)-energized mitochondria after 12-week treatment protocol for control (group A), high cholesterol diet (B), high cholesterol diet + captopril (C) and captopril (D) groups. All results are shown as means \pm SEM for $n=10$ animals for each group. $* P<0.05$ vs. control.

A and D. We showed that captopril does not adversely affect serum lipid levels. However, our data do not suggest favourable effects of captopril treatment in hypercholesterolemic rabbits. These results are consistent with many clinical studies showing that captopril does not significantly affect the serum lipid profile (Koh et al. 2010, Alves et al. 2004, Pollare et al. 1989, Krone and Nägele 1988).

Here we also show that basal oxygen consumption rate (state 4) of isolated cardiac mitochondria was significantly lower in rabbits on atherogenic diet and rabbits receiving captopril than in controls (Fig. 1A). The maximum oxygen consumption rate (state 3 ), was also significantly lower in groups $B$ and $\mathrm{D}$ than in group A (Fig. 1B). However, the ADP/O index of the isolated cardiac mitochondria was significantly lower in group B than in group A, while in group $\mathrm{D}$ this index was not significantly different compared with control (Fig. 2B). These results may suggest the presence of different mechanisms of oxygen consumption inhibition. The $\mathrm{ADP} / \mathrm{O}$ index was 3 or higher in group $\mathrm{A}$ and group $\mathrm{D}$, and reduction of this index suggests that, in addition to the process of oxidative phosphorylation, other oxygen consuming processes also take place in mitochondria.

Lipid peroxidation is the most commonly recognized one (Morrison et al. 1973, Chance and Williams 1956). Reduction of this ADP/O index in group $B$ coincides with increased oxidative stress (data not shown). Since there was no fall of ADP/O index in group $\mathrm{D}$, inhibition of mitochondrial respiration in group $\mathrm{D}$ is probably related to cardioprotective effects of 12-weeks treatment with captopril. These findings are in agreement with several studies showing cardioprotective effect of ACE-I (Penna et al. 2010, Al-Maghrebi et al. 2009, Chen et al. 2003, Vavrínková et al. 2001, Gvozdjáková et al. 1999, Yanagishita et al. 1997, Ma et al. 1996, Sanbe et al. 1995, Cholley et al. 1995). In contrast, other groups did not show any protective effect of captopril on mitochondrial function in heart and kidney of spontaneously hypertensive rats (Mujkosová et al. 2010, Rossi et al. 2003).

While $\mathrm{ADP} / \mathrm{O}$ ratios are used as an estimation of the capacity for energy production, the RCR reflects the tightness of coupling between respiration and oxidative phosphorylation in mitochondria. RCR values were comparable among the groups, ranging between 6.07 and 6.28 in all animals. These results indicate absence of chemiosmotic uncoupling in mitochondria of the rabbit heart. In group $\mathrm{C}$, captopril added to atherogenic diet restored the mitochondrial $\mathrm{QO}_{2}$, compared to atherogenic treatment. These observations are in agreement with Chowdhury et al. (2010) and de Cavanagh et al. (2003).

At an early stage of atherosclerosis, the treatment with different ACE inhibitors reduced endothelial dysfunction in atherogenic diet-fed (Becker et al. 1991) or hyperlipidemic rabbits (Chobanian et al. 1992). ACE-I can increase endothelial NO generation (Desideri et al. 2008). Essentially, NO can mediate cellprotective or cell-damaging reactions depending on the 
relative levels of $\mathrm{O}_{2}, \mathrm{NO}, \mathrm{O}_{2},-, \mathrm{H}_{2} \mathrm{O}_{2}$ and other oxidants (Brown and Borutaite 2007). Hence, based on the observed preservation of heart mitochondrial function in group D it can be assumed that in captopril-treated animals the higher levels of $\mathrm{NO}$, as well as the lower levels of $\mathrm{H}_{2} \mathrm{O}_{2}$ and $\mathrm{O}_{2}$.-, as compared with untreated control animals, led to the metabolization of NO through nondamaging routes. The reversible inhibition of mitochondrial respiration due to NO competition with oxygen for the building site on cytochrome oxidase probably explains the cardioprotective action of captopril (group D). Irreversible inhibition of mitochondrial respiration probably takes place in group B.

Our study has several limitations. We did not present biochemical markers of organ injury (reactive oxygen species, NO level, lipid peroxidation) that would provide additional information of the metabolic derangements of the animals during atherogenic diet and captopril treatment protocol. Also, we did not measure the plasma prekallikrein levels, which could be affected by ACE-I treatment. Furthermore, we did not assess the effect of captopril on mitochondrial permeability transition and apoptosis. We also did not monitor the effects of $\mathrm{AT}_{1}, \mathrm{AT}_{2}$ and bradykinin receptor antagonists that could provide additional information of the contribution of rennin-angiotensin-aldosteron system and bradykinin-kallikrein systems to cardiac metabolism in the course of hypercholesterolemia.

In conclusion, the ACE inhibitor captopril can protect against hypercholesterolemia-related cardiac mitochondrial dysfunction without lowering serum lipid levels in rabbits fed a high-cholesterol diet. Mitochondria isolated from rabbit hearts exposed hypercholesterolemic diet show reduced respiration rates (state 3 and state 4) with altering $\mathrm{ADP} / \mathrm{O}$ index, whereas the respiratory control ratio was not affected compared with control. Mitochondria isolated from rabbit hearts exposed captopril only shows reduced respiration rates without altering ADP/O index or respiratory control ratio. Cardiac mitochondrial respiration inhibition due to exposure to hypercholesterolemic diet was less severe in group $\mathrm{C}$ and D than in group B. Thus, our results suggest that other metabolic processes may be involved in the respiration inhibition induced by these treatments protocol. Despite captopril did not exert favorable effect on serum lipid levels, it restored mitochondrial oxygen consumption to the some extent in group C. Further studies should be performed to define the underlying physiological and (or pathophysiological) mechanisms and clinical implications.

\section{Conflict of Interest}

There is no conflict of interest.

\section{Acknowledgements}

Study supported by the research project from the Ministry of Science of the Serbia (175043).

\section{References}

AL-MAGHREBI M, BENTER IF, DIZ DI: Endogenous angiotensin-(1-7) reduces cardiac ischemia-induced dysfunction in diabetic hypertensive rats. Pharmacol Res 59: 263-268, 2009.

ALVES AC, MEDEIROS AM, FRANCISCO V, GASPAR IM, RATO Q, BOURBON M: Molecular diagnosis of familial hypercholesterolemia: an important tool for cardiovascular risk stratification. Rev Port Cardiol 29: 907-921, 2010.

ALVES RJ, DIAMENT J, AMÂNCIO RF, FORTI N, MARANHÃO RC: Lack of effect of captopril on the metabolism of an artificial lipid emulsion similar to chylomicrons in hypertensive hypercholesterolemic patients. Arq Bras Cardiol 83: 512-515 (in English), 508-511 (in Portuguese), 2004.

BECKER RHA, WIEMER G., LINZ W: Preservation of endothelial function by ramipril in rabbits on a long-term atherogenic diet. J Cardiovasc Pharmacol 18 (Suppl 2): S110-S115, 1991.

BROWN GC, BORUTAITE V: Nitric oxide and mitochondrial respiration in the heart. Cardiovasc Res 75: 283-290, 2007.

BROWN GC: Nitric oxide as a competitive inhibitor of oxygen consumption in the mitochondrial respiratory chain. Acta Physiol Scand 168: 667-674, 2000.

CHANCE B, AZZI A, LEE IY, LEE CP, MELA P: Structure and function. In: Mitochondria. L. ERNSTER, Z. DRAHOTA (eds), Academic Press, New York, NY, USA, 1969, pp 233-273.

CHANCE B, WILLIAMS GR: The respiratory chain and oxidative phosphorylation. Adv Enzymol 17: 54-134, 1956. 
CHAPMAN MJ: Animal lipoproteins: chemistry, structure, and comparative aspects. $J$ Lipid Res 21: 789-853, 1980.

CHEN JB, RAO BF, CHANG J, LIAO XG, CAO YD: Effects of captopril on myocardial energy metabolism in mice with viral myocarditis. (in Chinese) Zhongguo Wei Zhong Bing Ji Jiu Yi Xue 15: 485-488, 2003.

CHOBANIAN AV, HAUDENSCHILD C, NICKERSON C, HOPE S: Trandolapril inhibits atherosclerosis in theWatanabe heritable hyperlipidemic rabbit. Hypertension 20: 473-477, 1992.

CHOLLEY BP, SHROFF SG, SANDELSKI J, KORCARZ C, BALASIA BA, JAIN S, BERGER DS, MURPHY MB, MARCUS RH, LANG RM: Differential effects of chronic oral antihypertensive therapies on systemic arterial circulation and ventricular energetics in African-American patients. Circulation 91: 1052-1062, 1995.

CHOWDHURY SKR, SANGLE GV, XIE X, STELMACK GL, HALAYKO AJ, SHEN GX: Effects of extensively oxidized low-density lipoprotein on mitochondrial function and reactive oxygen species in porcine aortic endothelial cells. Am J Physiol Endocrinol Metab 298: E89-E98, 2010.

De CAVANAGH EM, PIOTRKOWSKI B, BASSO N, STELLA I, INSERRA F, FERDER L, FRAGA CG: Enalapril and losartan attenuate mitochondrial dysfunction in aged rats. FASEB J 17: 1096-1098, 2003.

DESIDERI G, GRASSI D, CROCE G, BOCALE R, TIBERTI S, EVANGELISTA S, NECOZIONE S, DI ORIO F, FERRI C: Different effects of angiotensin converting enzyme inhibitors on endothelin-1 and nitric oxide balance in human vascular endothelial cells: evidence of an oxidant-sensitive pathway. Mediators Inflamm 2008: 305087, 2008.

DORNAS WC, DE OLIVEIRA TT, AUGUSTO LEF, NAGEM TJ: Experimental atherosclerosis in rabbits. Arq Bras Cardiol 95: 272-278, 2010.

ESTABROOK RW: Mitochondrial respiratory control and the polarographic measurement of ADP:O ratios. In: Methods in Enzymology. R.W. ESTABROOK, M.E. PULLMAN (eds), Academic Press, New York, NY, USA, vol. 10, 1967, pp 41-47.

FRIEDEWALD WT, LEVY RI, FREDRICKSON DS: Estimation of the concentration of low-density lipoprotein cholesterol in plasma, without use of the preparative ultracentrifuge. Clin Chem 18: 499-502, 1972.

GVOZDJÁKOVÁ A, SIMKO F, KUCHARSKÁ J, BRAUNOVÁ Z, PSENEK P, KYSELOVIC J: Captopril increased mitochondrial coenzyme Q10 level, improved respiratory chain function and energy production in the left ventricle in rabbits with smoke mitochondrial cardiomyopathy. Biofactors 10: 61-65, 1999.

HÜNLICH M, HASENFUSS G: Effects of the NO donor sodium nitroprusside on oxygen consumption and energetics in rabbit myocardium. Basic Res Cardiol 104: 359-365, 2009.

JOHANNSEN DL, RAVUSSIN E: The role of mitochondria in health and disease. Curr Opin Pharmacol 9: 780-786, 2009.

KING CE, MELINYSHYN MJ, MEWBURN JD, CURTIS SE, WINN MJ, CAIN SM, CHAPLER CK: Canine hindlimb blood flow and $\mathrm{O}_{2}$ uptake after inhibition of EDRF/NO synthesis. $J$ Appl Physiol 76: 1166-1171, 1994.

KOH KK, HAN SH, OH PC, SHIN EK, QUON MJ: Combination therapy for treatment or prevention of atherosclerosis: focus on the lipid-RAAS interaction. Atherosclerosis 209: 307-313, 2010.

KOH KK, QUON MJ, HAN SH, LEE Y, KIM SJ, KOH Y, SHIN EK: Distinct vascular and metabolic effects of different classes of anti-hypertensive drugs. Int J Cardiol 140: 73-81, 2010.

KOWALTOWSKI AJ, SEETHARAMAN S, PAUCEK P, GARLID KD: Bioenergetic consequences of opening of the ATP-sensitive K channel of heart mitochondria. Am J Physiol Heart Circ Physiol 280: H649-H657, 2001.

LEE SH, DOLIBA NM, OSBAKKEN MD, OZ M, MANCINI D: Improvement of myocardial mitochondrial function following hemodyanamic support with left ventricular assist devices in patients with heart failure. $J$ Thorac Cardiovasc Surg 116: 344-349, 1998.

LOWRY OH, ROSEBROUGH NJ, FARR AL, RANDALL RJ: Protein measurement with the Folin phenol reagent. J Biol Chem 193: 265-275, 1951.

MA A, ZHANG W, LIU Z: Effect of protection and repair of injury of mitochondrial membrane-phospholipid on prognosis in patients with dilated cardiomyopathy. Blood Press Suppl 3: 53-55, 1996.

MANOLIS AJ, MARKETOU ME, GAVRAS I, GAVRAS H: Cardioprotective properties of bradykinin: role of the B(2) receptor. Hypertens Res 33: 772-777, 2010. 
MOGHADASIAN MH, FROHLICH JJ, MCMANUS BM: Advances in experimental dyslipidemia and atherosclerosis. Lab Invest 81: 1173-1183, 2001.

MONTECUCCO F, PENDE A, MACH F: The renin-angiotensin system modulates inflammatory processes in atherosclerosis: evidence from basic research and clinical studies. Mediators Inflamm 2009: 752406, 2009.

MORAIS KL, HAYASHI MA, BRUNI FM, LOPES-FERREIRA M, CAMARGO AC, ULRICH H, LAMEU C: Bj-PRO-5a, a natural angiotensin-converting enzyme inhibitor, promotes vasodilatation mediated by both bradykinin B(2) and M1 muscarinic acetylcholine receptors. Biochem Pharmacol 81: 736-742, 2011.

MUJKOSOVÁ J, ULICNÁ O, WACZULÍKOVÁ I, VLKOVICOVÁ J, VANCOVÁ O, FERKO M, POLÁK S, ZIEGELHÖFFER A: Mitochondrial function in heart and kidney of spontaneously hypertensive rats: influence of captopril treatment. Gen Physiol Biophys 29: 203-207, 2010.

PENNA C, TULLIO F, MORO F, FOLINO A, MERLINO A, PAGLIARO P: Effects of a protocol of ischemic postconditioning and/or captopril in hearts of normotensive and hypertensive rats. Basic Res Cardiol 105: 181$192,2010$.

POLLARE T, LITHELL H., BERNE CH: A comparison of the effects of hydrochlorothiazide and captopril on glucose and lipid metabolism in patients with hypertension. $N$ Engl J Med 321: 868-873, 1989.

PRATT RE: Angiotensin II and the control of cardiovascular structure. J Am Soc Nephrol 10 (Suppl 11): S120-S128, 1999.

ROSSI MA, RAMOS SG, PRADO CM: Chronic inhibition of nitric oxide synthase induces hypertension and cardiomyocyte mitochondrial and myocardial collagen remodelling in the absence of hypertrophy. J Hypertens. 21: 993-1001, 2003.

SANBE A, TANONAKA K, KOBAYASI R, TAKEO S: Effects of long-term therapy with ACE inhibitors, captopril, enalapril and trandolapril, on myocardial energy metabolism in rats with heart failure following myocardial infarction. J Mol Cell Cardiol 27: 2209-2222, 1995.

SCHMIEDER RE, HILGERS KF, SCHLAICH MP, SCHMIDT BM: Renin-angiotensin system and cardiovascular risk. Lancet 369: 1208-1219, 2007.

SHARPE N: The effects of ACE inhibition on progression of atherosclerosis. Review. J Cardiovasc Pharmacol 22 (Suppl 9): S9-S12, 1993.

SHEN W, HINTZE T, WOLLIN MS: Nitric oxide: an important signaling mechanisms between vascular endothelium and parenchimal cells in the regulation of oxygen consumption. Circulation 92: 3505-3512, 1995.

SHEN W, XU X, OCHOA M, ZHAO G, WOLIN MS, HINTZE T: Role of nitric oxide in the regulation of oxygen consumption in the conscious dogs. Circ Res 75: 1086-1095, 1994.

SHI L, MAO C, XU Z, ZHANG L: Angiotensin-converting enzymes and drug discovery in cardiovascular diseases. Drug Discov Today 15: 332-341, 2010.

VANHOUTTE PM: Regeneration of the endothelium in vascular injury. Cardiovasc Drugs Ther 24: 299-303, 2010.

VAVRÍNKOVÁ H, TUTTEROVÁ M, STOPKA P, DIVISOVÁ J, KAZDOVÁ L, DRAHOTA Z: The effect of captopril on nitric oxide formation and on generation of radical forms of mitochondrial respiratory chain compounds in ischemic rat heart. Physiol Res 50: 481-489, 2001.

WILLIAMS JG, RINCON-SKINNER T, SUN D, WANG Z, ZHANG S, ZHANG X, HINTZE TH: Role of nitric oxide in the coupling of myocardial oxygen consumption and coronary vascular dynamics during pregnancy in the dog. Am J Physiol Heart Circ Physiol 293: H2479-H2486, 2007.

YANAGISHITA T, TOMITA M, ITOH S, MUKAE S, ARATA H, ISHIOKA H, GESHI E, KONNO N, KATAGIRI T: Protective effect of captopril on ischemic myocardium. Jpn Circ J 61: 161-169, 1997.

ZENG D, ZHENG QS, OU DB: Triglyceride-mediated pathways and coronary heart disease. Lancet 376: 957, 2010. 